\title{
INDEKS KEPUASAN MASYARAKAT (IKM) DALAM PELAYANAN SIM PADA SATLANTAS POLRES DUMAI
}

\author{
Hildawati \\ Sekolah Tinggi Ilmu Administrasi Lancang Kuning Dumai \\ e-mail: hildawati.stiadmi@gmail.com
}

\begin{abstract}
Service quality is one of the important studies in bureaucratic reform. Until now, the problems of services provided by the government/ state to the people who make arrangements tend to still have many complaints. Such as the issue of service time which is not in accordance with the standards, convoluted service procedures to the problems of facilities and infrastructure which are considered to be less supportive of the implementation of services. At the Satllantas Polres Dumai, the same problems still occur, including in the service of obtaining a driver's license (SIM). Through Minister of Administrative Reform and Bureaucratic Reform Regulation Number 14 of 2017 concerning Guidelines for Preparing Community Satisfaction Surveys in this study a survey was conducted to find out people's perceptions and satisfaction with the services performed by the Satlantas Polres Dumai in servicing people who manage SIMs. The survey method refers to the provisions in the Minister of Administrative Reform and Bureaucratic Reform Regulation No. 14 of 2017 concerning Guidelines for Preparing the Community Satisfaction Survey. From the results of the study it is known that the IKM value of service quality in obtaining a SIM at the Satlantas Polres Dumai is 3.16 which is in the interval 2.51 - 3.25. Based on these results, the conversion value of IKM obtained is 78.94, which is in the intervals of $62.51-81.25$ with service quality is $B$ and service performance is categorized as GOOD
\end{abstract}

Keywords: Service Quality, Community Satisfaction Index, Service Performance

\begin{abstract}
Abstrak
Kualitas layanan adalah salah satu studi penting dalam reformasi birokrasi. Hingga saat ini, masalah layanan yang diberikan oleh pemerintah / negara kepada orang-orang yang melakukan pengaturan cenderung masih memiliki banyak keluhan. Seperti masalah waktu layanan yang tidak sesuai dengan standar, prosedur layanan berbelit-belit untuk masalah fasilitas dan infrastruktur yang dianggap kurang mendukung pelaksanaan layanan. Di Satllantas Polres Dumai, masalah yang sama masih terjadi, termasuk dalam layanan memperoleh SIM (SIM). Melalui Peraturan Menteri Pendayagunaan Aparatur Negara dan Reformasi Birokrasi Nomor 14 Tahun 2017 tentang Pedoman Penyusunan Survei Kepuasan Masyarakat dalam penelitian ini dilakukan survei untuk mengetahui persepsi dan kepuasan masyarakat terhadap layanan yang dilakukan oleh Satlantas Polres Dumai dalam melayani orang yang mengelola SIM. Metode survei mengacu pada ketentuan dalam Peraturan Menteri Reformasi Administrasi dan Reformasi Birokrasi No. 14 tahun 2017 tentang Pedoman Penyusunan Survei Kepuasan Masyarakat. Dari hasil penelitian diketahui bahwa nilai IKM kualitas layanan dalam memperoleh SIM di Satlantas Polres Dumai adalah 3,16 yang berada pada interval 2,51 - 3,25. Berdasarkan hasil ini, nilai konversi IKM yang diperoleh adalah 78,94, yang berada dalam interval 62,51 - 81,25 dengan kualitas layanan B dan kinerja layanan dikategorikan BAIK.
\end{abstract}

Kata Kunci : Kualitas Layanan, Indeks Kepuasan Masyarakat, Kinerja Layanan 


\section{PENDAHULUAN}

Pelayanan publik diera keterbukaan informasi pada perkembangan masyarakat menuntut penyedia pelayanan publik untuk bekerja dengan memenuhi kepuasan masyarakat. Tututan dan harapan pelayanan yang berkualitas pada Pemerintah sebagai central penyedia pelayanan menjadi sangat urgency bagi badan-badan atau lembaga penyedia pelayanan publik. Salah satu pelayanan yang masih menjadi fenomena ditengah-tengah masyarakat adalah pelayanan pada bidang perizinan. Pelayanan perizinan yang menyentuh langsung individu-individu adalah pelayanan Surat Izin Mengemudi (SIM) yang disediakan oleh SAMSAT. Menurut hasil kajian terdahulu Mandala dan Wahyuni (2017) masyarakat di Kabupaten Padeglang merasa puas dengan pelayanan yang diberikan SAMSAT. Hasil kajian ini membuktikan ada perbaikan dan perubahan pandangan bahwa lembaga SAMSAT sebagai penyedia layanan memenuhi keinginan masyarakat dan mengikuti keinginan kebijakan.

Berdasarkan objek penelitian yang dilakukan oleh peneliti Satlantas Polres Dumai masih cukup sering terjad keluhan masyarakat yang beragam, mulai dari prosedur yang dianggap terlalu panjang dan berbelit, adanya calo, dan sulitnya lulus tes uji praktek pengurusan SIM. Namun menyikapi hal tersebut, dalam pelayanan pengurusan SIM, Satlantas Polres Dumai mengkondisikan Satlantas untuk memberikan pelayanan yang berkualitas kepada masyarakat tetap diupayakan. Beberapa hal yang dilakukan adalah dengan melakukan pembaharuan dari berbagai aspek pelayanan, terutama dari segi penyediaan sarana dan prasarana pelayanan hingga peyanan yang berbasis teknologi dan informasi.

Perbaikan pelayanan ini dilakukan sesuai dengan salah satu konsep pelayanan publik dalam tubuh Kepolisian yaitu Pelayanan Prima yang termasuk dalam program Quick Wins. Quick Wins merupakan salah satu program pemerintah yang diadopsi oleh Kepolisian sebagai sasaran pelaksanaan pelayanan publik dengan daya ungkit kuat (key leverage) dan manfaatnya dapat langsung dirasakan oleh masyarakat, dan mampu direalisasikan serta hasilnya bisa diukur dalam $3-12$ bulan. Menyikapi upaya tersebut, pelaksanaan survey IKM dalam rangka mengimplementasikan Peraturan Menteri Pendayagunaan Aparatur Negara dan Reformasi Birokrasi Nomor 14 Tahun 2017 Tentang Pedoman Penyusunan Survey Kepuasan dapat menjadi tolak ukur untuk mengetuhi penilaian subjektif masyarakat terhadap pelayanan dalam pengurusan SIM pada Satlantas Polres Dumai.

Indeks Kepuasan Masyarakat dipilih menjadi metode dalam mengetahui kualitas pelayanan dalam pengurusan SIM sesuai dengan hasil observasi dilapangan, dimana terdapat beberapa indikator IKM yang masih belum dapat terpenuhi dengan baik. Berdasarkan hasil observasi kepada salah satu personil di Satpas SIM Satlantas Polres Dumai diketahui bahwa belum pernah dilakukan penelitian tentang Indeks Kepuasan Masyarakat (IKM) untuk mengetahui kualitas pelayanan dalam pengurusan SIM. Berdsarkan uraian diatas penulis tertarik untuk melakukan penelitian dengan judul: "Indeks Kepuasan Masyarakat (IKM) dalam pelaksanaan pelayanan pengurusan SIM pada Satlantas Polres Dumai"

\section{METODE}

Penelitian penelitian ini mengunakan metode mixed method dengan pendekatan penelitian survey (field research) dan riset kebijakan (Nazir, dan Majchrzak dalam Kadji (2016). Adapun teknik pengumpulan data yang digunakan dalam penelitian dengan Observasi, Angket, dan Wawancara. Sedangkan Populasi penelitiannya adalah seluruh masyarakat yang menjadi pemohon dalam pengurusan SIM pada Satlantas Polres Dumai. Dengan sampel penelitian sebesar 100 orang dari jumlah populasi penerima layanan dengan dasar Jumlah responden ini sesuai yang dipersyaratkan dalam kepmen PANRB No.16 tahun 2014 dengan Rumus: jumlah responden $=($ jumlah unsur +1$) \times 10=(9+1) \times 10=100$ 
responden. Analisis data menggunakan pengukuran Skala Likert. Dengan mengunakan 4 alternatif jawaban berjenjang (menggunakan empat skala Likert) yaitu: Untuk kategori tidak baik diberi nilai persepsi 1, kurang baik diberi nilai persepsi 2, baik diberi nilai persepsi 3, sangat baik diberi nilai persepsi 4.

Nilal IKM dihitung dengan menggunakan "nilai rata-rata tertimbang" masing-masing unsur pelayanan. Untuk menghitung Indeks Kepuasan Masyarakat terhadap 9 unsur pelayanan yang dikaji, setiap unsur pelayanan memiliki penimbang yang sama dengan rumus sebagai berikut:

$$
\text { Bobot Nilai Rata }- \text { rata Tertimbang }=\frac{\text { Jumlah Bobot }}{\text { Jumlah Unsur }}=\frac{1}{9}=0,11
$$

Sumber:Permenpan RB No.14 Tahun 2017

Selanjutnya untuk mendapatkan nilai IKM unit pelayanan digunakan pendekatan nilai rata-rata tertimbang dengan rumus sebagai berikut:

$$
I K M=\frac{\text { Total dari persepsi nilai per }- \text { unsur }}{\text { Penimbang total unsur yang ter }- \text { isi }} x \text { Nilai Penimbang }
$$

Sumber:Permenpan RB No.14 Tahun 2017

Untuk memudahkan interpretasi terhadap penilaian IKM yaitu antara 25 - 100 maka hasil penilaian tersebut di atas dikonversikan dengan nilai dasar 25, dengan rumus sebagai berikut:

\section{Nilai IKM Unit Pelayanan $x 25$}

Sumber:Permenpan RB No.14 Tahun 2017

Hasil perhitungan diatas selanjutnya dikategorikan sebagai berikut:

Tabel 1. Nilai Persepsi, Interval IKM, Interval Konversi IKM, Mutu Pelayanan dan Kinerja Unit Pelayanan

\begin{tabular}{ccccc}
\hline $\begin{array}{c}\text { Nilai } \\
\text { Persepsi }\end{array}$ & $\begin{array}{c}\text { Nilai Interval } \\
\text { IKM }\end{array}$ & $\begin{array}{c}\text { Nilai Interval } \\
\text { Konversi IKM }\end{array}$ & $\begin{array}{c}\text { Mutu } \\
\text { Pelayanan }\end{array}$ & $\begin{array}{c}\text { Kinerja Unit } \\
\text { Pelayanan }\end{array}$ \\
\hline 1 & $1,00-1,75$ & $125,00-43,75$ & D & Tidak Baik \\
\hline 2 & $1,76-2,50$ & $243,76-62,50$ & C & Kurang Baik \\
\hline 3 & $2,51-3,25$ & $62,51-81,25$ & B & Baik \\
\hline 4 & $3,26-4,00$ & $481,26-100$ & A & Sangat Baik \\
\hline
\end{tabular}

1. Jawaban responden dikonversikan dengan angka 1, 2, 3 dan 4. 
2. Nilai rata-rata per unsur yang ditanyakan diperoleh dengan cara jumlah nilai per unsur dibagi dengan jumlah responden

3. Nilai tertimbang diperoleh dengan cara seluruh nilai rata-rata per unsur dijumlahkan dan dikalikan dengan konstanta 0,11 .

Sedangkan nilai Indeks Kepuasan Masyarakat (IKM) diperoleh dari nilai tertimbang dikalikan dengan Angka 25.

\section{HASIL DAN PEMBAHASAN}

Pelayanan publik menjadi sangat penting dalam meningkatkan kepuasan masyarakat. Kepuasan masyarakat akan muncul dengan adanya kepercayaan akibat pelayanan cepat, ramah dan sarana prasarana yang mendukung pelayanan yang diberikan kepada masyarakat (Saputra, Marlinda, Sufi, 2019). Berkaitan dengan itu dalam objek penelitian ditemukan Indeks Kepuasan Masyarakat dipengaruhi oleh kualitas pelayanan yang diperoleh masyarakat pada Stlantas Polres Dumai pelayanan SIM, ini akan dilihat dari analisis Identitas Responden yang mendapatkan pelayanan.

\section{A. Analisis Identitas Responden}

Identitas responden dalam penelitian ini dianalisis berdasarkan beberapa kategori yaitu jenis kelamin, umur, pendidikan dan pekerjaan. Adapun uraiannya yaitu:

1. Identitas Responden Berdasarkan Jenis Kelamin

Berdasarkan data yang telah terkumpul, identitas responden berdasarkan jenis kelamin dapat dilihat pada grafik berikut:

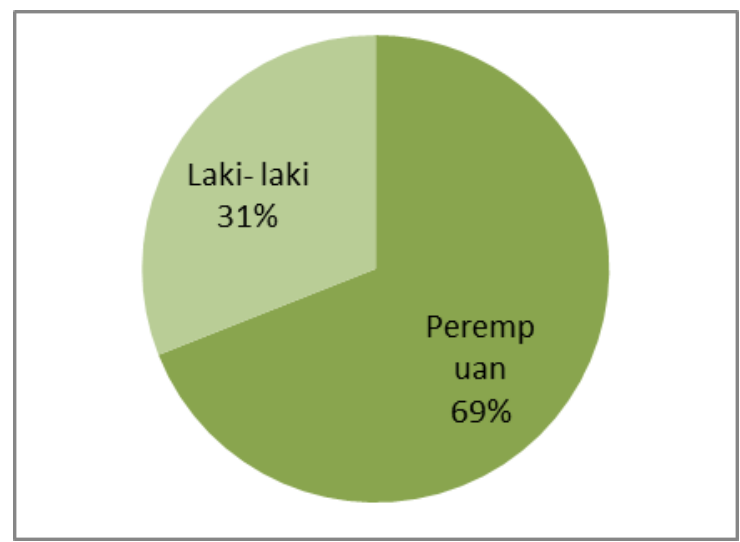

Sumber: Olahan Data Primer, 2019

2. Identitas Responden Berdasarkan Umur

Berdasarkan data yang telah terkumpul, identitas responden berdasarkan Umur dapat dilihat pada grafik berikut: 


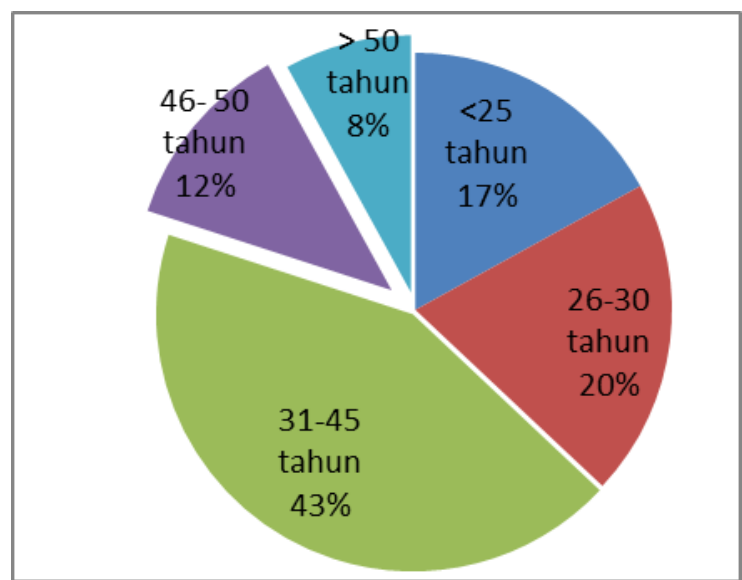

Sumber: Olahan Data Primer, 2019

3. Identitas Responden Berdasarkan Tingkat Pendidikan

Berdasarkan data yang telah terkumpul, identitas responden berdasarkan Tingkat Pendidikan dapat dilihat pada grafik berikut:

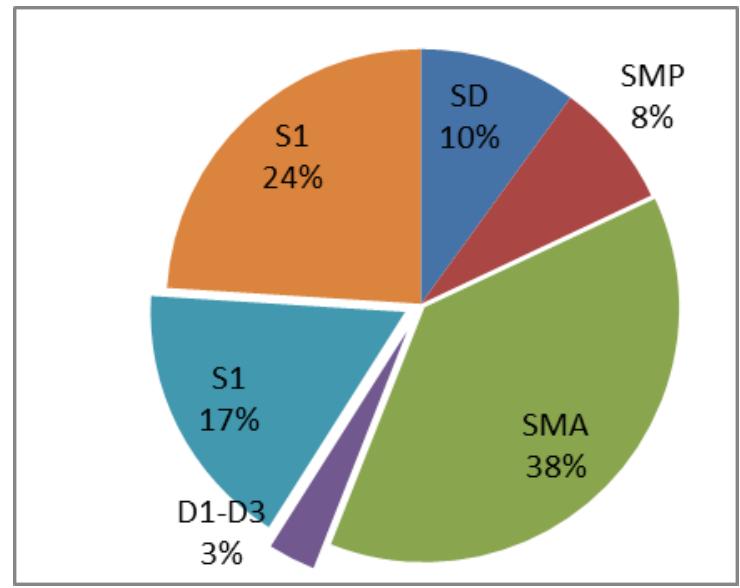

Sumber: Olahan Data Primer, 2019

4. Identitas Responden Berdasarkan Pekerjaan

Berdasarkan data yang telah terkumpul, identitas responden berdasarkan Pekerjaan dapat dilihat pada grafik berikut:

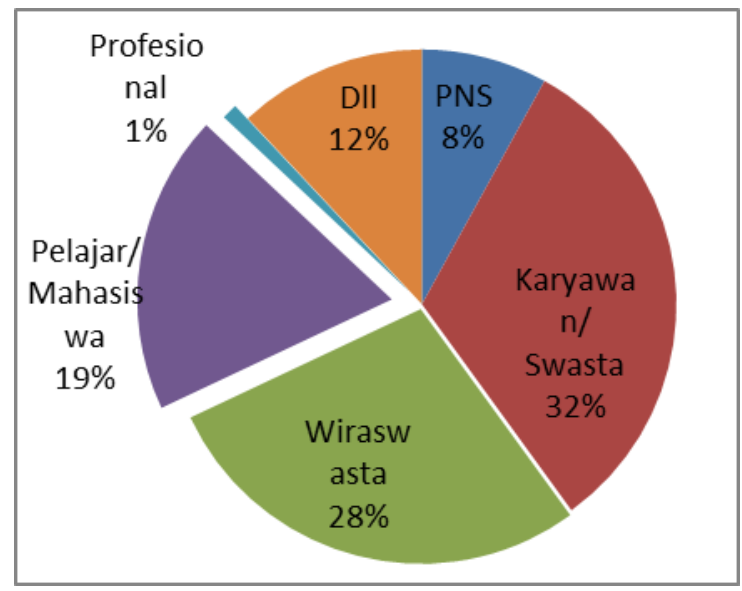

Sumber: Olahan Data Primer, 2019 


\section{B. Analisis Indeks Kepuasan Masyarakat}

Analisis Indeks Kepuasan Masyarakat (IKM) dalam pelayanan pengurusan SIm pada Satlantas Polres Dumai dilakukan secara menyeluruh meliputi 9 indikator yang ada. Analisis ini dilakukan dengan cara menghitung nilai indeks dari unit pelayanan kinerja secara keseluruhan. Adapun nilai indeks diperoleh dengan cara mengalikan masing-masing nilai rata-rata unsur dengan bobot nilai rata-rata tertimbang. Berikut ini di sajikan penilaian unsur indeks kepuasan masyarakat dalam pelayanan pengurusan SIM pada Satlantas Polres Dumai.

Nilai IKM dari indikator pelayanan menunjukkan penilaian masyarakat terhadap indikator pelayanan tersebut. Berikut ini hasil penelitian Indeks Kepuasan Masyarakat (IKM) dari masing-masing Indikator:

\section{Persyaratan}

Dari Indikator persyaratan disediakan 3 butir pertanyaan. Adapun Nilai IKM untuk Persyaratan dalam pelayanan pengurusan SIM pada Satlantas Polres Dumai dapat dilihat pada tabel berikut:

Tabel 2. IKM Terhadap Persyaratan dalam Pelayanan Pengurusan SIM

\begin{tabular}{clc}
\hline No & \multicolumn{1}{c}{ Pertanyaan } & $\begin{array}{c}\text { Tanggapan } \\
\text { Responden }\end{array}$ \\
\hline 1 & $\begin{array}{l}\text { Tingkat keterbukaan mengenai } \\
\text { persyaratan pelayanan }\end{array}$ & 313 \\
\hline 2 & $\begin{array}{l}\text { Tingkat kemudahan dalam mengurus } \\
\text { dan memenuhi persyaratan pelayanan }\end{array}$ & 319 \\
\hline 3 & $\begin{array}{l}\text { Tingkat kejelasan mengenai } \\
\text { persyaratan pelayanan }\end{array}$ & 304 \\
\hline Total Rata-Rata Tanggapan & 312.00 \\
\hline NRR & 3.12 \\
\hline & Nilai IKM Indikator 1 & 78.00 \\
\hline & Kinerja
\end{tabular}

Sumber: Olahan Data Primer, 2019

\section{Prosedur}

Dari Indikator Prosedur disediakan 3 butir pertanyaan. Adapun Nilai IKM untuk Prosedur dalam pelayanan pengurusan SIM pada Satlantas Polres Dumai dapat dilihat pada tabel berikut:

Tabel 3. IKM Terhadap Prosedur dalam Pelayanan Pengurusan SIM

\begin{tabular}{clc}
\hline No & \multicolumn{1}{c}{ Pertanyaan } & $\begin{array}{c}\text { Tanggapan } \\
\text { Responden }\end{array}$ \\
\hline 1 & $\begin{array}{l}\text { Tingkat keterbukaan informasi } \\
\text { mengenai prosedur pelayanan }\end{array}$ & 283 \\
\hline 2 & $\begin{array}{l}\text { Tingkat kejelasan alur dalam prosedur } \\
\text { pelayanan }\end{array}$ & 284 \\
\hline 3 & $\begin{array}{l}\text { Tingkat kesederhanaan prosedur } \\
\text { pelayanan }\end{array}$ & 266 \\
\hline \multicolumn{2}{c}{ Total Rata-Rata Tanggapan } & 277.67 \\
\hline
\end{tabular}




\begin{tabular}{cc}
\hline NRR & 2.78 \\
\hline Nilai IKM Indikator 1 & 69.42 \\
\hline Kinerja & Baik \\
\hline
\end{tabular}

Sumber: Olahan Data Primer, 2019

\section{Waktu Pelayanan}

Dari Indikator Waktu Pelayanan disediakan 2 butir pertanyaan. Adapun Nilai IKM untuk Waktu Pelayanan dalam pengurusan SIM pada Satlantas Polres Dumai dapat dilihat pada tabel berikut:

Tabel 4. IKM Terhadap Waktu pelayanan dalam Pengurusan SIM

\begin{tabular}{clc}
\hline No & \multicolumn{1}{c}{ Pertanyaan } & $\begin{array}{c}\text { Tanggapan } \\
\text { Responden }\end{array}$ \\
\hline 1 & $\begin{array}{l}\text { Tingkat ketepatan waktu proses } \\
\text { pelayanan }\end{array}$ & 299 \\
\hline 2 & $\begin{array}{l}\text { Tingkat keterbukaan waktu } \\
\text { penyelesaian pelayanan }\end{array}$ & 305 \\
\hline & Total Rata-Rata Tanggapan & 302.00 \\
\hline NRR & 3.02 \\
\hline Nilai IKM Indikator 1 & 75.50 \\
\hline Kinerja & Baik
\end{tabular}

Sumber: Olahan Data Primer, 2019

\section{Biaya/Tarif}

Dari Indikator Biaya/ Tarif disediakan 4 butir pertanyaan. Adapun Nilai IKM untuk Biaya/ Tarif dalam pelayanan pengurusan SIM pada Satlantas Polres Dumai dapat dilihat pada tabel berikut:

Tabel 5. IKM Terhadap Biaya/Tarif dalam Pelayanan Pengurusan SIM

\begin{tabular}{clc}
\hline No & \multicolumn{1}{c}{ Pertanyaan } & $\begin{array}{c}\text { Tanggapan } \\
\text { Responden }\end{array}$ \\
\hline 1 & $\begin{array}{l}\text { Tingkat kejelasan mengenai rincian } \\
\text { biaya pelayanan }\end{array}$ & 301 \\
\hline 2 & $\begin{array}{l}\text { Tingkat keterbukaan mengenai rincian } \\
\text { biaya pelayanan }\end{array}$ & 314 \\
\hline 3 & $\begin{array}{l}\text { Tingkat keterjangkauann biaya } \\
\text { pelayanan oleh kemampuan } \\
\text { masyarakat }\end{array}$ & 296 \\
\hline 4 & $\begin{array}{l}\text { Tingkat kewajaran antara biaya } \\
\text { pelayanan dengan hasil pelayanan }\end{array}$ & 305 \\
\hline \multicolumn{2}{c}{ Notal Rata-Rata Tanggapan } & 304.00 \\
\hline \multicolumn{2}{c}{ Nilai IKM Indikator 1 } & 3.04 \\
\hline \multicolumn{2}{c}{ Kinerja } & Baik \\
\hline
\end{tabular}

Sumber: Olahan Data Primer, 2019 


\section{Produk Spesifikasi Jenis Pelayanan}

Dari Indikator Produk Spesifikasi Jenis Pelayanan disediakan 3 butir pertanyaan. Adapun Nilai IKM untuk Produk Spesifikasi Jenis Pelayanan dalam pengurusan SIM pada Satlantas Polres Dumai dapat dilihat pada tabel berikut:

Tabel 6. IKM Terhadap Produk Spesifikasi Jenis Pelayanan dalam Pengurusan SIM

\begin{tabular}{ccc}
\hline No & Pertanyaan & $\begin{array}{c}\text { Tanggapan } \\
\text { Responden }\end{array}$ \\
\hline $1 \quad$ Akurasi produk layanan & 315 \\
\hline Total Rata-Rata Tanggapan & 315.00 \\
\hline NRR & 3.15 \\
\hline & Nilai IKM Indikator 1 & 78.75 \\
\hline Kinerja & Baik
\end{tabular}

Sumber: Olahan Data Primer, 2019

\section{Kompetensi Pelaksana}

Dari Indikator Kompetensi disediakan 3 butir pertanyaan. Adapun Nilai IKM untuk Kompetensi dalam pelayanan pengurusan SIM pada Satlantas Polres Dumai dapat dilihat pada tabel berikut:

Tabel 7. IKM Terhadap Kompetensi Pelaksana dalam

Pelayanan Pengurusan SIM

\begin{tabular}{clc}
\hline No & \multicolumn{1}{c}{ Pertanyaan } & $\begin{array}{c}\text { Tanggapan } \\
\text { Responden }\end{array}$ \\
\hline 1 & Tingkat kemampuan fisik petugas & 309 \\
\hline 2 & $\begin{array}{l}\text { Tingkat kemampuan } \\
\text { intelektualitas petugas }\end{array}$ & 316 \\
\hline 3 & $\begin{array}{l}\text { Tingkat kemampuan administrasi } \\
\text { petugas }\end{array}$ & 319 \\
\hline \multicolumn{2}{c}{ Total Rata-Rata Tanggapan } & 314.67 \\
\hline \multicolumn{2}{c}{ NRR } & 3.15 \\
\hline \multicolumn{2}{c}{ Nilai IKM Indikator 1 } & 78.67 \\
\hline
\end{tabular}

Sumber: Olahan Data Primer, 2019

\section{Perilaku Pelaksana}

Dari Indikator Perilaku Pelaksana disediakan 3 butir pertanyaan. Adapun Nilai IKM untuk Perilaku Pelaksana dalam pelayanan pengurusan SIM pada Satlantas Polres Dumai dapat dilihat pada tabel berikut:

Tabel 8. IKM Terhadap Perilaku Pelaksana dalam Pelayanan Pengurusan SIM

\begin{tabular}{clc}
\hline No & \multicolumn{1}{c}{ Pertanyaan } & $\begin{array}{c}\text { Tanggapan } \\
\text { Responden }\end{array}$ \\
\hline 1 & $\begin{array}{l}\text { Tingkat kesopanan dan keramahan } \\
\text { petugas pelayanan }\end{array}$ & 326 \\
\hline 2 & $\begin{array}{l}\text { Tingkat penghormatan dan } \\
\text { penghargaan anatara petugas }\end{array}$ & 318 \\
\hline
\end{tabular}




\begin{tabular}{|c|c|c|}
\hline 3 & $\begin{array}{l}\text { Tingkat kredibilitas petugas } \\
\text { pelayanan }\end{array}$ & 322 \\
\hline & Total Rata-Rata Tanggapan & 322.00 \\
\hline & NRR & 3.22 \\
\hline & Nilai IKM Indikator 1 & 80.50 \\
\hline & Kinerja & Baik \\
\hline
\end{tabular}

Sumber: Olahan Data Primer, 2019

\section{Penanganan Pengaduan, Saran dan Masukan}

Dari Indikator Penanganan Pengaduan, Saran dan Masukan disediakan 3 butir pertanyaan. Adapun Nilai IKM untuk Penanganan Pengaduan, Saran dan Masukan dalam pelayanan pengurusan SIM pada Satlantas Polres Dumai dapat dilihat pada tabel berikut:

Tabel 9. IKM Terhadap Penanganan Pengaduan, Saran dan Masukan dalam Pengurusan SIM

\begin{tabular}{clc}
\hline No & \multicolumn{1}{c}{ Pertanyaan } & $\begin{array}{c}\text { Tanggapan } \\
\text { Responden }\end{array}$ \\
\hline 1 & Ketersediaan kotak saran & 296 \\
\hline 2 & Penangan Pengaduan & 332 \\
\hline 3 & $\begin{array}{l}\text { Respon terhadap saran dan } \\
\text { masukan }\end{array}$ & 302 \\
\hline \multicolumn{2}{c}{ Total Rata-Rata Tanggapan } & 310.00 \\
\hline \multicolumn{2}{c}{ NRR } & 3.10 \\
\hline & Nilai IKM Indikator 1 & Baik \\
\hline
\end{tabular}

Sumber: Olahan Data Primer, 2019

\section{Sarana dan Prasarana}

Dari Indikator Sarana dan Prasarana disediakan 3 butir pertanyaan. Adapun Nilai IKM untuk Sarana dan Prasarana dalam pelayanan pengurusan SIM pada Satlantas Polres Dumai dapat dilihat pada tabel berikut:

Tabel 10. IKM Terhadap Sarana dan Prasarana dalam Pelayanan Pengurusan SIM

\begin{tabular}{clc}
\hline No & \multicolumn{1}{c}{ Pertanyaan } & $\begin{array}{c}\text { Tanggapan } \\
\text { Responden }\end{array}$ \\
\hline 1 & $\begin{array}{l}\text { Tingkat kesopanan dan } \\
\text { keramahan petugas pelayanan }\end{array}$ & 322 \\
\hline 2 & $\begin{array}{l}\text { Tingkat penghormatan dan } \\
\text { penghargaan anatara petugas } \\
\text { dengan masyarakat. }\end{array}$ & 308 \\
\hline 3 & $\begin{array}{l}\text { Tingkat kredibilitas petugas } \\
\text { pelayanan }\end{array}$ & 324 \\
\hline Total Rata-Rata Tanggapan & 318.00 \\
\hline
\end{tabular}




\begin{tabular}{cc}
\hline Nilai IKM Indikator 1 & 79.50 \\
\hline Kinerja & Baik \\
\hline
\end{tabular}

Sumber: Olahan Data Primer, 2019

Dari hasil uraian perindikator pelayanan dapat diketahui bahwa dari 9 indikator penelitian mutu pelayanan setiap indikator mendapatkan nilai 'B" atau kinerja pelayanannya dikategorikan Baik. Namun meskipun demikian dapat dilihat juga bahwa terdapat nilai IKM yang berbeda antara satu indikator dengan indikator yang lainnya.

Jika dilihat dari masing-masing indikator Indeks Kepuasan Masyarakat (IKM) yang mengacu pada pengkategorian mutu pelayanan maka nilai IKM dari setiap indikator dapat dilihat pada tabel berikut:

Tabel 11. Hasil Indeks Kepuasan Masyarakat (IKM) Per-indikator Pelayanan

\begin{tabular}{clcccc}
\hline No & \multicolumn{1}{c}{ Indikator } & Nilai IKM & $\begin{array}{c}\text { Nilai } \\
\text { Konversi } \\
\text { IKM }\end{array}$ & $\begin{array}{c}\text { Mutu } \\
\text { Pelayanan }\end{array}$ & Kinerja \\
\hline 1 & Persyaratan & 3.12 & 78.00 & B & Baik \\
\hline 2 & Prosedur & 2.78 & 69.42 & B & Baik \\
\hline 3 & Waktu Pelayanan & 3.02 & 75.50 & B & Baik \\
\hline 4 & Biaya/ Tarif & 3.04 & 76.00 & B & Baik \\
\hline 5 & $\begin{array}{l}\text { Produk Spesifikasi Jenis } \\
\text { Pelayanan }\end{array}$ & 3.15 & 78.75 & B & Baik \\
\hline 6 & Kompetensi Pelaksana & 3.15 & 78.67 & B & Baik \\
\hline 7 & Perilaku Pelaksana & 3.22 & 80.50 & B & Baik \\
\hline 8 & $\begin{array}{l}\text { Penanganan Pengaduan, } \\
\text { Saran dan Masukan }\end{array}$ & 3.10 & 77.50 & B & Baik \\
\hline 9 & Sarana dan Prasarana & 3.18 & 79.50 & B & Baik \\
\hline & $\quad$ IKM & $\mathbf{3 . 1 6}$ & $\mathbf{7 8 . 9 4}$ & B & Baik
\end{tabular}

\section{Sumber:Olahan Data Primer,2019}

Jika hasil tabel diatas di konversikan dengan tabel 1, maka dapat dilihat Nilai IKM dari kualitas pelayanan dalam pengurusan SIM pada Satlantas Polres Dumai adalah 3.16 yang berada pada interval 2,51 - 3,25. Berdasarkan hasil tersebut Nilai konversi IKM yang diperoleh adalah sebesar 78.94 yang berada pada interval 62,51 - 81,25 dengan Mutu pelayanan adalah B dan Kinerja pelayanan dikategorikaan BAIK.

Dalam membuat formulasi konsep pelayanan public, ada dua kata kunci yang melekat secara simultan yang dapat diperhatikan yaitu yang pertama adalah pelayanan publik identik dengan kebutuhan warga Negara/ masyarakat sedangkan yang kedua adalah pelayan public selalu berkaitan dengan tugas dan tanggung jawab pemerintah/ Negara. Mengacu pada hal tersebut, Ulum (2018: 7) menjelaskan bahwa pelayanan public adalah suatu aktifitas yang dilakukan oleh pemerintah dalam mengurus segala hal yang dibutuhkan masyarakat. Dalam konteks ini, fungsi pemerintah melalui aparatnya adalah sebagai public servant. Artinya, tugas aparatur pemerintah adalah melayani kepentingan masyarakat sesuai dengan aturan yang berlaku. 
Memberikan pelayanan publik merupakan salah satu peran dan kewajiban pemerintah untuk memenuhi hak warga negaranya. Menurut Mindarti (2016:2) Esensi pelayanan adalah suatu proses yang terdiri dari serangkaian tindakan, interaksi, aktifitas penting untuk menyampaikan jasa kepada pelanggan. Aktifitas pelayanan yang dilakukan berkaitan dengan upaya-upaya untuk memberikan pelayanan yang paling tepat kepada pengguna jasa. Seperti yang disebutkan oleh Mohr dan Bitner dalam Mindarti (2016:2) bahwa aktifitas pelayanan dicirikan lekat dengan persoalan krusiaal seputar "the manner in which the outcome is transferred to the costumer".

Di Indonesia, pelayanan publik meupakan kebutuhan dasar warga Negara yang hars dipenuhi oleh Negara. Untuk itu Negara harus memberikan jaminan bahwa setiap warga negaranya mendapatkan akses pelayanan tersebut sesuai dengan yang diamanatkan dalam Undang-undang Dasar 1945 pasal 28C ayat 1. Dalam Dwiyanto (2017:33) disebutkan bahwa Pemerintah membuat standar minimal pelayanan yang mengatur bagaimana daerah harus mengelola penyelenggaraan layanan publik.

Menurut David McKevit dan Allan Lawton dalam Saggaf (2018:162) disebutkan bahwa pelayanan public diorientasikan pada suatu upaya untuk menterjemahkan kandungan sektor public, tidak sekedar hanyak penyampaian pelayanan (service delivery). Pelayanan public diorientasikan harus mampu mendefinisikan $3 \mathrm{C}$ (consumerisme, caring and citizenshipand the greates of these is citizenship) perlindungan kewarganegaraan.

Agar pelayanan dapat memuaskan orang atau kelompok orang lain yang dilayani, maka pelaku yang bertugas melayani harus memenuhi empat kriteria pokok, seperti yang dinyatakan Moenir dalam Tangkilisan (2007:208) yaitu:

1. Tingkah laku yang sopan

2. Cara menyampaikan ssuatu yang berkaitan dengan apa yang seharusnya diterima oleh orang yang bersangkutan

3. Waktu menyampaikan yang tepat

4. Keramahtamahan

Untuk mengukur kinerja pelayanan dapat menggunakan instrument pengukuran kinerja yang dikemukakan oleh Zeithaml, Parasuraman dan Berry dalam Ratminto (2018:1) yang menjelaskan bahwa ada 10 indikator kinerja pelayanan yaitu:

1. Kenampakan fisik (tangible)

2. Reliablitas (Reliability)

3. Responsivitas (Responsiveness)

4. Kompetensi (Competensi)

5. Kesopanan (Courtesy)

6. Kredibilitas (Credibility)

7. Keamanan (Security)

8. Akses (Access)

9. Komunikasi (Communication)

10. Pengertian (Understanding the costumer)

Menurut Yusriadi (2018:63) Konteks pelaksanaan pelayanan publik sesuai dengan konsep reformasi birokrasi memiliki system dan prosedur kerja yang berprinsisp good governance yang menekankan pada transparansi, akuntabilitass dan pertisipasi masyarakat. Melalui SOP (Standar Operasional prosedur) dapat dipastikan adanya transparansi karena masyarakat dapat mengetahu mekanisme alur pelayanan publik serta terbuka bagi masyarakat untuk menyampaikan keluhan dan informasi balik tentang perlakuan pelayanan melalui Indeks Kepuasan Masyarakat (IKM). Survey IKM dalam rangka pelaksaaan Peraturan Menteri Pendayagunaan Aparatur Negara dan Reformasi Birokrasi Nomor 14 Tahun 2017 Tentang Pedoman Penyusunan Survey Kepuasan. 
Dalam Ulum (2018:13) dijelaskan bahwa Survey Kepuasan Masyarakat (SKM) adalah kegiatan pengukuran secara komprehensif tentang tingkat/indeks kepuasan masyarakat yang diperoleh dari hasil pengukuran atas pendapat masyarakat dalam memperoleh pelayanan dari penyelengaraan pelayanan public. Urgensi pelaksanaan SKM selain untuk mengukur kepuasan masyarakat, juga untuk meningkatkan kualitas penyelengaraan pelayanan publik. Lebih lanjut lagi Ulum (2018:13) menjelaskan bahwa dengan melaksanakan SKM diharapkan dapat:

1. Memberikan informasi mengenai kelemahan dan kekuatan daru maasing- masing unit penyelenggara pelayanan publik

2. Mengukur secara berkala penyelenggaraan pelayanan yang telah dilaksanakan oleh unit pelaynan publik.

3. Menjadi bahan penetapan kebijakan yang perlu diambil dan langkah perbaikan pelayanan

4. Sebagai umpan balik dalam memperbaiki (kualitas) pelayanan.

Dalam penelitian ini, pengukuran Indeks kepuasan Masyarakat dalam pelayanan pengurusan SIM pada Satlantas Polres Dumai didasarkan pada Peraturan Menteri Pendayagunaan Aparatur Negara dan Reformasi Birokrasi Nomor 14 Tahun 2017 Tentang Pedoman Penyusunan Survey Kepuasan Masyarakat Unit Penyelenggaraan Pelayanan Publik yang terdiri dari 9 ruang lingkup antara lain: Ruang lingkup Survey Kepuasan Masyarakat dalam peraturan ini meliputi:

1. Persyaratan

Persyaratan adalah syarat yang harus dipenuhi dalam pengurusan suatu jenis pelayanan, baik persyaratan teknis maupun administratif.

2. Prosedur

Prosedur adalah tata cara pelayanan yang dibakukan bagi pemberi dan penerima pelayanan, termasuk pengaduan.

3. Waktu pelayanan

Waktu pelayanan adalah jangka waktu yang diperlukan untuk menyelesaikan seluruh proses pelayanan dari setiap jenis pelayanan.

4. Biaya/Tarif

Biaya/Tarif adalah ongkos yang dikenakan kepada penerima layanan dalam mengurus dan/atau memperoleh pelayanan dari penyelenggara yang besarnya ditetapkan berdasarkan kesepakatan antara penyelenggara dan masyarakat

5. Produk Spesifikasi Jenis Pelayanan

Produk spesifikasi jenis pelayanan adalah hasil pelayanan yang diberikan dan diterima sesuai dengan ketentuan yang telah ditetapkan. Produk pelayanan ini merupakan hasil dari setiap spesifikasi jenis pelayanan.

6. Kompetensi Pelaksana

Kompetensi Pelaksana adalah kemampuan yang harus dimiliki oleh pelaksana meliputi pengetahuan, keahlian, keterampilan, dan pengalaman.

7. Perilaku Pelaksana

Perilaku Pelaksana adalah sikap petugas dalam memberikan pelayanan. Maklumat Pelayanan adalah merupakan pernyataan kesanggupan dan kewajiban penyelenggara untuk melaksanakan pelayanan sesuai dengan standar pelayanan.

8. Penanganan Pengaduan, Saran dan Masukan

Penanganan pengaduan, saran dan masukan, adalah tata cara pelaksanaan penanganan pengaduan dan tindak lanjut.

9. Sarana dan prasarana

Sarana adalah segala sesuatu yang dapat dipakai sebagai alat dalam mencapai maksud dan tujuan. Prasarana adalah segala sesuatu yang merupakan penunjang utama terselenggaranya suatu proses (usaha, 
pembangunan, proyek). Sarana digunakan untuk benda yang bergerak (komputer, mesin) dan prasarana untuk benda yang tidak bergerak (gedung).

\section{KESIMPULAN}

Berdasarkan paparan hasil penelitian dan pembahasan diatas, dapat disimpulkan sebagai berikut:

1. Berdasarkan perhitungan Indeks Kepuasan Masyarakat yang mengacu pada Peraturan Menteri Pendayagunaan Aparatur Negara dan Reformasi Birokrasi Nomor 14 Tahun 2017 Tentang Pedoman Penyusunan Survey Kepuasan Masyarakat, maka diperoleh angka indeks sebesar 78.94 yang berada pada interval 62,51 - 81,25. Dari hasil tersebut dapat dikatakan kualitas pelayanan publik berada pada tingkat "B". Hal ini menunjukkan bahwa kinerja pelayanan pengurusan SIM pada Satlantas Polres Dumai secara keseluruhan termasuk dalam kategori Baik

2. Berdasarkan 9 indikator pelayanan yang diteliti, Perilaku Pelaksana pelayanan merupakan indikator dengan nilai indeks tertinggi dengan nilai IKM sebesar 80.50 dan berada pada tingkat baik. Sedangkan indikator dengan nilai indeks terendah yaitu indikator Prosedur dengan nilai IKM sebesar 69.42 dan berada pada tingkat Baik.

\section{SARAN}

Beberapa saran bedasarkan hasil penelitian yaitu:

1. Pelayanan dalam pengurusan SIM pada Satlantas Polres Dumai daari hasil penelitian dikategorikan Baik. Untuk kedepannya maka, pelayanan secara keseluruhan dapat dipertahankan dipertahankan atau jika mungkin akan sangat baik untuk beberapa indikator tetap menjadi perhatian untuk ditingkatkan menjadi lebih baik lagi.

2. Unsur Perilaku Pelaksana pelayanan dengan nilai IKM tertinggi perlu untuk tetap dipertahankan. Dalam pelayanan kepada masyarakat yang melakukan pengurusan SIM keramahan, kesopanan dan tanggung jawab pegawai dapat dipertahankan dan semakin ditingkatkan agar hasilnya lebih baik lagi.

3. Prosedur pelayanan merupakan unsur dengan nilai IKM terendah dibandingkan dengan unsur lainnya, oleh karena itu Satlantas Polres Dumai harus berupaya untuk memperbaiki tingkat prosedur pelayanan yang diberikan sehingga pelayanan tidak lagi dianggap berbelit belit dan menyulitkan masyarakat

\section{DAFTAR PUSTAKA}

[1] Mandala, A., Anggraeni, S., \& Wahyuni, N. (2017). Indeks Kepuasan Masyarakat Terhadap Pelayanan Publik SAMSAT Kabupaten Pandeglang. Jurnal Teknik Industri Untirta.. Jurnal Teknik Industri (Vol.4.No.2. 2016)

[2] Saputra, T., Marlinda, P., \& Sufi, W. Implementasi Kebijakan Inovasi Pelayanan Publik Di Puskesmas Jaya Mukti Dalam Meningkatkan Kepuasan Masyarakat.Jurnal Niara (Vol.11.No.2.2019 Hal:177-188)

[3] Dwiyanto, Agus. 2017. Manajemen Pelayanan Publik Peduli, Inklusif dan Kolaboratif. Yogyakarta: Gajah Mada University Press. 
[4] Kadji, Yulianto. 2016. Metode Penelitian Ilmu Administrasi. Yogyakarta: Deepublish

[5] Mindarty, Leli Indah. 2016. Manajemen Pelayanan Publik Menuju Tata Kelola Yang Baik. Malang: UB Press.

[6] Morrisan.2012. Metode Penelitian Survey.Jakarta:Penerbit Kencana

[7] Ratminto,dkk. 2018. Pelayanan Prima Pedoman Penerapan Moment Kritis Pelayanan dai A sampai Z. Yogyakarta: UGM Press

[8] Saggaf, Said dan Haedar Akib. 2018. Reformasi Pelayanan Publik di Negara Berkembang. Makasar:CV. Sah Media

[9] Tangkilisan, Hessel Nogi S.2007. Manajemen Publik. Jakarta: Penerbit PT.Grasindo

[10] Ulum, Mochamad Chazienul. 2018. Public Service: Tinjauan Teoretis dan Isu-Isu Strategis Pelayanan Publik. Malang: UB Press

[11] Yusriadi. 2018. Reformasi Birokrasi dalam Pelayanan Publik. Yogyakarta:Deepublish

[12] Yusuf, Muri A. 2014. Penelitian Kuantitatif, Kualitatif dan Penelitian Gabungan. Jakarta: Penerbit Kencana 